10-1-1987

\title{
The effect of feedback on student use of interpersonal communication skills.
}

David G. Dunning

University of Nebraska Medical Center, ddunning@unmc.edu

Brian M. Lange

University of Nebraska Medical Center, blange@unmc.edu

Tell us how you used this information in this short survey.

Follow this and additional works at: https://digitalcommons.unmc.edu/cod_articles

Part of the Dentistry Commons

\section{Recommended Citation}

Dunning, David G. and Lange, Brian M., "The effect of feedback on student use of interpersonal communication skills." (1987). Journal Articles: College of Dentistry. 15.

https://digitalcommons.unmc.edu/cod_articles/15

This Article is brought to you for free and open access by the College of Dentistry at DigitalCommons@UNMC. It has been accepted for inclusion in Journal Articles: College of Dentistry by an authorized administrator of DigitalCommons@UNMC.For more information, please contact digitalcommons@unmc.edu. 


\title{
Brief Communications
}

\section{The Effect of Feedback on Student Use of Interpersonal Communication Skills}

\author{
David G. Dunning, M.A.; Brian M. Lange, Ph.D.
}

B ehavioral scientists share a paradoxical vision about the importance of interpersonal skills in dentistry. This vision consists of two distinct images. The first depicts interpersonal communication as "the other side of dentistry in the clinic," ${ }^{\prime 1}$ equal in importance to technical competence. This image implies that technical competence represents merely a "hygiene" factor in patient motivation, ${ }^{2}$ with interpersonal communication being the true motivator of patients. Nordstrom et al. succinctly summarize the second image: "There is a growing concern among dental and dental hygiene educators about the lack of skills students have in patient management by the completion of their clinical training. ${ }^{\prime 3}$ The paradox of the vision is this: interpersonal communication is viewed as critically important, yet educating students in interpersonal skills is seen as problematic, costly, and time-consuming.

Research on teaching interpersonal communication to medical and dental students has stressed the influence of various instructional methods, including videotape feedback. ${ }^{4-16}$ Where reported, the dependent measures typically consist of global ratings on humanistic skills (such as empathy and genuineness) or similar scales of effectiveness. Researchers base these ratings on both simulated ${ }^{4-9}$ and actual ${ }^{10-16}$ studentpatient interviews. The most recent reports in the dental literature examine the influence of videotape feedback from actual appointments on simulated clinical encounters and student self-reports ${ }^{17}$ and describe the use of a behaviorally based interpersonal checklist to evaluate dental students' oral diagnoses, where students are taped a second time only if skill deficits warrant. $^{18}$

No report in the dental literature describes the effect of feedback from videotapes of actual clinical appointments on subsequent clinical appointments using a behavioral instrument. The purpose of this article is to report such a study.

Mr. Dunning is instructor, and Dr. Lange is associate professor, both in the Department of Community Dentistry, College of Dentistry, University of Nebraska Medical Center, Lincoln, NE 68583-0740. Address correspondence and reprint requests to Mr. Dunning.

\section{Methods}

Senior students in the 1987 graduating class of the University of Nebraska Medical Center's College of Dentistry were oriented to a videotaping requirement in a meeting in May 1986. Students were informed that two restorative appointments would be randomly selected for videotaping during their senior year and that a 20 to 30-minute feedback conference using a standardized evaluation form and videotaped segments of appointments would be held within eight days of each taping. Students received a form summarizing the interpersonal communication skills that would be evaluated.

Two groups of students were selected randomly for the study. An experimental group of 21 students would be videotaped and evaluated once during the 1986 summer session and again during the fall session. A control group of 21 students would be videotaped and evaluated for the first time during fall 1986, with a subsequent session in the spring. Videotaping the control group while withholding the conference was viewed by the authors as an attractive but unethical research procedure because of its unequal treatment of students. Students were unaware of their assignment to these groups.

The intervention with the experimental group consisted of three components: (1) student viewing of their first taped appointment, (2) a feedback conference held within eight days of the first taping, and (3) a feedback summary form from the first taping given to and discussed with students a few days before their second taping.

The dependent variables in this study consisted of ratings on an evaluation instrument described in more detail elsewhere. ${ }^{19}$ Eight behaviors at the start and nine behaviors at the end of an appointment are rated on a simple yes/no scale. Examples of behaviors at the start of an appointment include referring to the patient by name, updating the medical history, and asking if the patient has any questions. At the end of an appointment, behaviors include instructing the patient about sensitivity, scheduling the next appointment, and encouraging the patient to call if dental problems arise. 
The behaviors during the middle of the appointment are rated on more sophisticated subscales indicative of the quality and/or quantity of behavior. Behaviors evaluated during the middle of the appointment include answering questions, forewarning the patient about potentially uncomfortable procedures, reinforcing patient behavior, and checking on patient comfort.

Group performances in each behavior at the start, middle, and end of appointments thus served as the dependent variables. The figures used in the statistical analysis were percentages of group members who scored "yes" on the behaviors at the start and end of the appointment and who scored at or above acceptable levels on the individual behaviors in the middle of the appointment.

To demonstrate that feedback intervention accounted for changes in student interpersonal skills, the research design controlled for the influence of student maturation by pairing in time the experimental group's second taping with the control group's first taping. Two members of each group were usually taped each week throughout the fall session. Three one-tailed ttests $(\alpha=.05)$ were employed in each of three comparisons: (1) experimental group performance in the second taping vs. the first taping, (2) experimental group performance in the second taping vs. the control group performance, and (3) experimental group performance in the first taping vs. control group performance.

\section{Results}

Because one rater evaluated 95 percent of the videotape appointments, a measure of the intrarater reliability was more appropriate than an interrater reliability esti-

Table 1. Statistical Comparisons of Groups

\begin{tabular}{|c|c|c|c|}
\hline \multirow{3}{*}{$\begin{array}{l}\text { Independent } \\
\text { Variables }\end{array}$} & \multicolumn{3}{|c|}{ Dependent Variables } \\
\hline & Appointment & Appointment & Appointment \\
\hline & Start & Middle & End \\
\hline \multicolumn{4}{|c|}{ Experimental group 1st vs. 2nd taping* } \\
\hline Means & $60.3 / 77.4$ & $61.9 / 73.2$ & $60.2 / 77.8$ \\
\hline SDs & 28.6/22.1 & $25.9 / 24.2$ & $35.9 / 21.7$ \\
\hline $\mathrm{p}$ values & $.018+$ & $.002+$ & $.017+$ \\
\hline \multicolumn{4}{|c|}{ Experimental group 2 nd taping vs. control* } \\
\hline Means & $77.4 / 50.6$ & $73.2 / 61.1$ & $77.8 / 66.3$ \\
\hline SDs & $22.1 / 24.1$ & $24.2 / 25.2$ & $21.7 / 30.3$ \\
\hline p values & $.001+$ & $.0003 t$ & $.029 t$ \\
\hline \multicolumn{4}{|c|}{ Experimental group 1st taping vs. control ${ }^{* *}$} \\
\hline Means & $60.3 / 50.60$ & $61.9 / 61.1$ & $60.2 / 66.3$ \\
\hline SDs & $28.6 / 34.9$ & $25.9 / 25.2$ & $35.9 / 30.3$ \\
\hline p values & .290 & .475 & .351 \\
\hline
\end{tabular}

"Paired comparison.

tp< 0.05 .

"Independent comparison. mate. Four randomly selected appointments from the first semester, two from each group, were reevaluated a minimum of seven weeks after the initial evaluation. Intrarater reliability estimates were computed by dividing the number of ratings in agreement by the total number possible. The mean intrarater reliability was .89 , with a range from .81 to .94 . The overall .89 measure is substantially higher than the .70 minimally acceptable reliability recommended by Bowers and Courtright. ${ }^{20}$

Table 1 presents group means, standard deviations, and levels of significance for each of the three comparisons. The comparison of the experimental group's first and second tapings showed that scores for the beginning, middle, and end were significantly higher at the second taping. Similarly, when compared to the control group, the experimental group's scores for the second taping were significantly higher. Finally, none of the comparisons of the control group with the experimental group's first taping showed any significant difference.

\section{Discussion}

The results demonstrate the effectiveness of feedback for student acquisition of interpersonal skills, since the experimental group's second performance was significantly better than its first. Further, maturation in the absence of feedback, in this instance approximately four months of clinical experience, seems to have little bearing on student communicative performance, since the experimental group's performance in the first taping did not differ significantly from the control group's performance.

There are several possible reasons for the relative strengths and weaknesses in student interpersonal skills. The necessity of the behaviors evaluated, the rigor of the standards, and student motivation are among the strongest reasons. A few of the behaviors evaluated with the instrument may be perceived by students as relatively unimportant. For example, at the start of appointments, student explanations of how an appointment fits into the overall treatment plan are evaluated for each appointment even though providing such explanations every third or fourth appointment probably would suffice. Further, students justifiably may believe that explanations of equipment need not be offered more than 14 percent (control group) to 22 percent (experimental group second taping) of the time. These explanations are most appropriate with newer patients who are relatively unfamiliar with the student and/or the procedures.

The relative rigor of the standards of some of the evaluated behaviors may account for apparently weak student performance. This is particularly true in the area of reinforcing patient behavior and checking on patient comfort. Expecting students to reinforce patients once for every three commands/requests and to 
check patient comfort every 12 minutes may be too rigorous. Only further research on specific patient expectations can clarify the frequency with which some of these behaviors ought to be performed. As Rankin and Harris' research shows, certain patient variables such as anxiety influence patient expectations. ${ }^{21}$

The lack of student feedback to patients on oral hygiene deserves mention. Only seven reinforcing statements for home care were given in the 63 appointments in this study. In previous studies, there were ten reinforcements during 94 evaluated appointments in the 1986 graduating class and none in 25 observed appointments in the 1985 graduating class. Patients need and deserve more feedback on their home care.

The most important limitations of this study include the lack of follow-up to assess long-term retention of interpersonal skills and the inability to generalize these findings. Long-term follow-up is infeasible due to limited resources and graduating students. Because this study included one class from one dental school, its findings are obviously not generalizable to other colleges, although the authors believe that the intervention would be successful in other environments.

Given these results, future research in teaching interpersonal skills to health providers might be directed toward identifying effective communication behaviors in other specific health care contexts (for example, prosthodontics and orthodontics) based in part on patient information needs and expectations. ${ }^{22}$ Also the effect of intervening variables, such as cognitive style, personality type, gender, and locus of control, on student acquisition of these behaviors should be examined. Some students probably benefit more than others from videotape feedback. Relationships between interpersonal behavior, intervening variables, and feedback need to be studied to maximize student learning.

\section{REFERENCES}

1. Mealiea W. Patient management, teaching the other side of dentistry in the clinic. Presentation at the 63rd AADS Annual Session, Washington, DC, 1986.
2. Herzberg F, Mausner B, Synderman B. The Motivation to Work 2nd ed. New York: Wiley, 1959.

3. Nordstrom N, De Vore C, Clark P. Promotion of effective patient practitioner interaction. J Dent Educ [Abstract] 1986;50:49-50.

4. Linton J, McCutcheon W, Stevenson J. Teaching behavioral principles to dental students; a pilot course. J Dent Educ 1975;39:149. 51.

5. Bird J, Lindley P. Interviewing skill: the effects of ultra-brief training for general practitioners - a preliminary report. Med Educ 1979;13:349-55.

6. Hannay D. Teaching interviewing with simulated patients. Med Educ 1980;14:246-8.

7. Jackson E. Convergent evidence for the effectiveness of interpersonal skill training for dental students. J Dent Educ 1978;42:517. 23.

8. Werner A, Schneider J. Teaching medical students interactional skills, N Engl J Med 1974;290:1232-7.

9. Horst G, Leeds J, Hoogstraten J. Effectiveness of communication skills training for dental students. Psych Rep 1984;55:7-11.

10. Hollifield G, Rousell C, Bachrach A. A method of evaluating student-patient interviews. J Med Educ 1957;32:853-8.

11. Scott N, Donnelly M, Gallagher R, Hess J. Interaction analysis as a method for assessing skill in relating to patients: studies on validity. Brit J Med Educ 1973;7:174-8.

12. Cassata D, Conroe R, Clements P. A program for enhancing medical interviewing using video-tape feedback in the family practice residency. J Fam Pract 1977;4:673-7.

13. Maguire P, Roe P, Goldberg D, Jones S, Hyde C, O'Dowd T. The value of feedback in teaching interviewing skills to medical students. Psych Med 1978;8:695-704.

14. Pilowsky I. The interrupted interview: a method for facilitating the development of clinical observational skills. Med Educ 1978;12:357-9.

15. Junek W, Burra $P$, Leickner $P$. Teaching interviewing skills by encountering patients. J Med Educ 1979;54:402-7.

16. Kent G, Clarke P, Dabrymple-Smith D. The patient is the expert:a technique for teaching interviewing skills. Med Educ 1981;15:3642.

17. Davis E, Nicosia N, Ferry G, Morphis W. Effect of instructor. guided videotape feedback of clinical encounters on student selfassessment of communication skills. I Dent Educ [Abstract] 1987;51:37.

18. Urtz F, Jakubowski J, Shane N, Gilgenbach-Burr C. Clinical prac tice in behavioral management and interpersonal communica tion: a criterion-based teaching program. J Dent Educ [Abstract]1978;51:37-8.

19. Dunning D, Lange B. Communication tendencies of senior dental students. J Dent Educ 1986;50:172-5.

20. Bowers J, Courtright J. Communication research methods. Glenview, Illinois: Scott, Foresman \& Co., 1984:118.

21. Rankin J, Harris M. Patient's preferences for dentist's behaviors. JADA 1985;110:323-7.

22. Kreps G, Query J. Assessment and testing in the health professions. Paper presented at the Speech Communication Association Convention, Chicago, Illinois, November 1986, p 19. 